\title{
An update on the clinical utility of extracorporeal photopheresis in the treatment of graft-versus-host disease
}

This article was published in the following Dove Press journal:

International Journal of Clinical Transfusion Medicine

29 March 2017

Number of times this article has been viewed

\author{
Baheyeldin Salem ${ }^{1,2}$ \\ Jennifer Webb ${ }^{3}$ \\ David Alex Jacobsohn ${ }^{1,2}$ \\ 'Blood and Marrow Transplant \\ Program, ${ }^{2}$ Department of Paediatrics, \\ ${ }^{3}$ Department of Transfusion Medicine, \\ Children's National Health System, \\ Washington, DC, USA
}

\begin{abstract}
Graft-versus-host disease (GVHD) continues to be a major complication following allogeneic hematopoietic cell transplantation (allo-HCT) with high morbidity and mortality. Corticosteroids are the first-line treatment for GVHD; however, a substantial number of patients go on to require second-line treatment where no single therapeutic modality has been proven to be the most effective. Extracorporeal photopheresis (ECP) is an efficient and established therapy for cutaneous T-cell lymphoma, GVHD, rejection after solid organ transplantation and various autoimmune diseases. Although large randomized trials are limited, there is compelling cumulative data on the efficacy of ECP for GVHD, and the response rates, especially for cutaneous involvement, are encouraging. ECP has an excellent safety profile, a well-documented steroid-sparing effect, proven survival benefit and overall quality-of-life improvement. In many institutions, ECP is commonly regarded as the preferred second-line treatment for GVHD.
\end{abstract}

Keywords: GVHD, ECP, immunosuppressive therapy, IST, apheresis, steroid-refractory graft-versus-host disease, hematopoietic cell transplantation, graft versus leukemia effect

\section{Introduction}

Allogeneic hematopoietic cell transplantation (allo-HCT) remains the only known curative therapeutic modality for various malignant and nonmalignant disorders. Despite recent advances in conditioning regimens, human leukocyte antigen (HLA)-matching procedures and supportive care, there remains a substantial morbidity and mortality associated with HCT. Nonrelapse mortality is largely attributable to graft-versus-host disease (GVHD), both acute and chronic forms of the disease. ${ }^{1,2}$

In an analysis of 1,270 patients surviving $>2$ years after allo-HCT, GVHD accounted for $12 \%$ of deaths surpassed only by recurrence of primary disease ${ }^{3}$ and up to $15 \%$ of deaths following unrelated donor transplant. ${ }^{4}$

Systemic immunosuppressive therapy (IST) remains the standard approach for the treatment of GVHD, the duration of which can be prolonged particularly in chronic GVHD (cGVHD), which occurs in $\sim 50 \%$ of patients. ${ }^{5,6}$ Corticosteroids remain the standard first-line IST for GVHD. ${ }^{7-9}$ This pharmacological approach is effective only in $\sim 50 \%$ of patients; ${ }^{10}$ moreover, its use is limited by toxicity.

Despite a wide variety of second-line systemic IST options, there is no standard of care for those who do not respond to steroids as first-line treatment. ${ }^{11}$ Patients with steroid-refractory (SR) acute GVHD (aGVHD) or cGVHD are frequently offered participation in clinical trials if possible to help identify optimal second-line therapy. If trials are unavailable or patients are ineligible, the choice of second-line therapy is largely based on institutional practices and physician preference. Extracorporeal 
photopheresis (ECP) offers a potential therapeutic advantage in patients with GVHD. ${ }^{12,13}$ In 1994, Owisanowski et al ${ }^{14}$ reported the first case of cGVHD successfully treated with ECP. The authors reported a case of a 43-year-old female with acute myeloid leukemia (AML) who developed cGVHD with severe sclerodermatous manifestations that was successfully treated with ECP after lack of response to cyclosporine, lowdose steroids and psoralen ultraviolet A (PUVA) therapy.

ECP is an apheresis-based immunomodulatory therapy. Whole blood is removed from the patient, and centrifugation is used to separate out the leukocyte-enriched buffy coat, rich with peripheral blood mononuclear cells (PBMCs). These cells are exposed to the photosensitizing drug 8-methoxypsoralen (8-MOP) and are then irradiated with ultraviolet A (UVA) light. The photoactivated buffy coat is then re-infused into the patient.

The type of vascular access necessary to complete a course of ECP is determined by multiple factors, including patient size, anticipated duration of procedures, need for a blood prime and adequacy of peripheral access. Though older adolescents and adults may be able to tolerate ECP using peripheral veins, the frequency and duration of therapy often necessitate a central line in younger children. For those patients who are $<40 \mathrm{~kg}$ and therefore require a blood prime, manufacturer guidelines recommend double-lumen, apheresis-compatible access (Therakos, Inc. Westchester, PA, USA).

The technology and equipment involved with ECP therapy have evolved. Originally, ECP was a discontinuous or "offline" apheresis procedure that involved separate collection, activation and infusion steps. External UVA irradiation is applied after collection, which has been performed on the Amicus, Optia and Cobe Spectra platforms. However, modern machines use intermittent or continuous PBMC collection techniques and are able to photoactivate and infuse all with the same machine. This is considered an "online" technique. This technology was developed by Therakos, Inc. with a majority of the procedures in the United States involving the Therakos Uvar XTS system (second-generation model). This machine uses an intermittent separation process, which may be problematic in patients weighing $<40 \mathrm{~kg}$ or those with a pre-procedural hematocrit $<30 \%$ because of the volume of extracorporeal blood required. More recently, in 2009, the third-generation Therakos Cellex device has become available with advances including continuous-flow separation technology, shorter treatment times (1.5 versus 3 hours) and reduced extracorporeal blood volumes allowing for lower weight patients to safely undergo the procedure. ${ }^{15}$ Brosig et al prospectively compared offline versus online systems. Notable differences were seen in the cellular composition of the two methods. Offline methods collected buffy coats that were enriched with CD16+ mononuclear cells. In contrast, online method displayed enrichment of nonclassical monocytes. However, the clinical significance of these findings is unclear. ${ }^{16}$

Our group here at Children's National compared the two most frequently used instruments, the Uvar XTS and Cellex, by performing a retrospective analysis of 10 pediatric patients who have received ECP for SR-GVHD (both acute and chronic). Compared to the Uvar XTS1 instrument, use of the Cellex instrument resulted in shorter runtimes, increased percentage of mononuclear cells treated, reduced incidence of line occlusions requiring tissue plasminogen activator (TPA) treatment and decreased incidence of patient-related complications. ${ }^{17}$

ECP received US Food and Drug Administration (FDA) approval in the late 1980s for the palliative treatment of skin manifestations in patients with cutaneous T-cell lymphoma (CTCL) unresponsive to other forms of treatment. In this disease, ECP is thought to elicit an immunostimulatory effect against neoplastic cells. ${ }^{18}$

The precise mechanism by which ECP improves outcomes in GVHD is unknown. During ECP, PBMCs are exposed to 8-MOP that covalently binds and cross-links DNA upon exposure to UVA light irradiation resulting in apoptosis. This appears to exert an immunomodulatory effect against T-cell-mediated disorders such as GVHD. ${ }^{19-25}$ It is believed that ECP-induced lymphocyte apoptosis stimulates the differentiation of monocytes into immature dendritic cells (DCs) that can then become active antigen-presenting cells (APCs) and cytokine producers. ${ }^{26}$ Reports of cytokine responses post ECP have demonstrated an increased production of immunosuppressive cytokines interleukin (IL)-10 and IL-1 Ra. ${ }^{27}$ APCs that have phagocytized apoptotic T-cells present antigen to T-cells in lymph nodes and spleen, which results in antigen-specific T-regulatory cells (T-regs) that are specific for the pathogenic T-cell clones. This downregulation of alloreactivity of T-lymphocytes by ECP was demonstrated in several early in vitro studies that have showed inactivation of T-lymphocytes by treatment with 8-MOP and UVA. ${ }^{28-35}$ This has been confirmed in an experimental bone marrow transplant (BMT) murine model, where the photoinactivation of donor cells with 8-MOP and UVA prior to infusion prevented the onset of GVHD. ${ }^{36}$

\section{Clinical experience for aGVHD}

To date, there is no optimal or standard therapeutic option for second-line treatment of SR-aGVHD. Despite a large 
number of studies, choice of second-line agent/therapy varies between institutions and among different transplant physicians. Table 1 summarizes the outcome to ECP use as a second-line treatment for aGVHD.

In 2012, Martin et $\mathrm{al}^{11}$ published recommendations of the American Society of Blood and Marrow Transplantation for the treatment of aGVHD based on a comprehensive and critical review of published reports. Across the 67 selected studies, data on complete response (CR) and partial response (PR) of aGVHD and 6-month survival did not support the choice of any specific agent for second-line therapy. Besides horse antithymocyte globulin (ATG), ECP was the most frequently studied therapeutic option.

Messina et $\mathrm{al}^{37}$ treated 33 patients with aGVHD at four pediatric hospitals where they observed a CR of $76 \%$ in skin, $60 \%$ in the liver and $75 \%$ in gastrointestinal (GI) tract. The 5 -year overall survival (OS) was $69 \%$ among responders versus $12 \%$ for nonresponders $(p=0.001)$.

Greinix et al $^{38}$ conducted a prospective Phase II study on ECP in 59 adult patients with severe aGVHD. Compared to the pilot study, intensification of ECP therapy to two to three treatments per week on a weekly basis was performed. Compared to the pilot study, this regimen led to improved CR rates in patients with grade IV aGVHD (60\% versus $12 \%)$ and GI involvement (73\% versus 25\%). Overall CR rates were $82 \%, 60 \%$ and $61 \%$ in patients with skin, GI and liver aGVHD. In patients who responded to ECP, steroids could be discontinued at a median of 55 days (range 17-287 days) after start of ECP. In univariate analysis, a lower grade of aGVHD, fewer organs involved at the start of first-line therapy with corticosteroids as well as at the start of ECP, and a lower cumulative corticosteroid dose prior to ECP, significantly increased the probability of achieving a CR. However, after multivariate logistic regression analysis, only a lower grade of aGVHD at the start of ECP and later onset of corticosteroid medication after HSCT were variables significantly favoring the achievement of CR by ECP.

Jagasia et $\mathrm{al}^{39}$ compared ECP to anticytokine therapy consisting of inolimumab or etanercept as second-line treatment for SR-aGVHD patients. Fifty-seven patients received ECP compared to 41 patients receiving anticytokine treatment. Rate of CR was significantly higher in the ECP cohort compared to the anticytokine therapy cohort (54\% versus $20 \%, p=0.001$ ), respectively. In multivariable analyses, ECP, adjusted for corticosteroid dose and grade of aGVHD, was an independent predictor of response and was associated with superior survival (hazard ratio [HR] 4.6, $p=0.016$ ) in patients with corticosteroid-refractory aGVHD grade II.

In addition to its use as a second-line treatment for GVHD, preliminary studies have evaluated the role of ECP as a preventative approach for GVHD and as a part of myeloablative conditioning regimen. Shaughnessy et $\mathrm{al}^{40}$ assessed the effectiveness of ECP for the prevention of aGVHD in a Phase II multicenter study where ECP was administered to 62 patients before standard myeloablative conditioning regimen combined with cyclosporine A (CSA) and methotrexate for GVHD prophylaxis. Results were compared to the Center for International Blood and Marrow Transplant Research (CIBMTR) historical control group. Grades II-IV aGVHD developed in $22(36 \%)$ of the 62 subjects, including nine $(30 \%)$ of 30 related donor HCT recipients and $13(41 \%)$ of 32 matched unrelated or one HLA-mismatched related donor HCT recipients. A 100-day cumulative incidence (CI) of aGVHD grades II-IV was reported as $35 \%$ and 1 -year

Table I Published response rates for ECP as a second-line treatment for aGVHD

\begin{tabular}{|c|c|c|c|c|c|c|c|c|}
\hline Author (year) & Study type & $\begin{array}{l}\text { Patients }(\mathbf{n}) / \\
\text { patient population }\end{array}$ & $\%$ ORR & $\begin{array}{l}\% \text { CR/PR } \\
\text { skin }\end{array}$ & $\begin{array}{l}\% \text { CR/PR } \\
\text { gut }\end{array}$ & $\begin{array}{l}\% \text { CR/PR } \\
\text { liver }\end{array}$ & $\%$ OS & Reference \\
\hline Salvaneschi et al (200I) & Phase I/II & 9/pediatric & $78(7 / 9)$ & $67(6 / 9)$ & $60(3 / 5)$ & $33(1 / 3)$ & $67(6 / 9)$ & 13 \\
\hline Messina et al (2003) & Retrospective & 33/pediatric & & $76(25 / 33)$ & $75(15 / 20)$ & $60(9 / 15)$ & 69 at 5 years & 37 \\
\hline Garban et al (2005) & Pilot & I2/adult & $75(9 / 12)$ & $67(8 / 12)$ & $40(2 / 5)$ & $0(0 / 2)$ & 42 & 67 \\
\hline Greinix et al (2006) & Phase II & 59/adult & & $82(47 / 57)$ & $60(9 / 15)$ & $60(14 / 23)$ & 47 at 5 years & 38 \\
\hline Berger et al (2007) & Retrospective & I5/pediatric & $67(10 / 12)$ & $85(11 / 13)$ & $60(6 / 10)$ & $71(5 / 7)$ & $67(10 / 15)$ & 68 \\
\hline Kanold et al (2007) & Prospective & 12/pediatric & $83(10 / 12)$ & $90(9 / 10)$ & $83(5 / 6)$ & $56(5 / 9)$ & 75 at $8.5 \mathrm{mo}$ & 57 \\
\hline Calore et al (2008) & Retrospective & I5/pediatric & $100(15 / 15)$ & $92(12 / 13)$ & $71(10 / 14)$ & $100(1 / I)$ & 85 at 5 years & 69 \\
\hline Perfetti et al (2008) & Retrospective & 23/adult & $52(\mathrm{CR})$ & $65(15 / 23)$ & $27(3 / 11)$ & $40(8 / 12)$ & 48 at $37 \mathrm{mo}$ & 70 \\
\hline Gonzalez-Vicent et al (2008) & Prospective & 8/pediatric & & $91(10 / 11)$ & $62.5(5 / 8)$ & $75(3 / 4)$ & $55(6 / I I)$ & 71 \\
\hline Perotti et al (20l0) & Prospective & 50/pediatric & $68(34 / 50)$ & $83(39 / 47)$ & $73(8 / I I)$ & $67(16 / 24)$ & 64 at I year & 58 \\
\hline Gonzalez et al (2010) & Retrospective & 2l/adult & $90(19 / 21)$ & & & & & 72 \\
\hline Jagasia et al (20I3) & Retrospective & 57/adult & 66 & & & & 60 & 39 \\
\hline Berger et al (2014) & Retrospective & $34 /$ mixed & 65 & & & & & 73 \\
\hline
\end{tabular}

Abbreviations: aGVHD, acute graft-versus-host disease; CR, complete response; ECP, extracorporeal photopheresis; mo, months; ORR, overall response rate; OS, overall survival; PR, partial response. 
CI of cGVHD as $38 \%$. Compared to 347 matched historical controls from the CIBMTR, the ECP-treated cohort had a lower rate of grades II-IV aGVHD. Adjusted OS at 1 year was $83 \%$ in the ECP study group and $67 \%$ in the historical control group (relative risk 0.44 ). The results from this study support the prophylactic benefit of ECP as well as survival advantage over historical control that merits further evaluation as a preventive measure. Miller et $\mathrm{al}^{41}$ showed a lower than expected incidence of severe aGVHD when ECP was used as part of a novel reduced-intensity conditioning regimen with pentostatin and low-dose total body irradiation (TBI). The regimen had low incidence of transplant-related mortality and no negative effects on engraftment or disease relapse.

Kitko et $\mathrm{al}^{42}$ conducted a prospective Phase II clinical trial that incorporated tacrolimus, mycophenolate mofetil (MMF), etanercept and ECP as GVHD prophylaxis in 48 patients (median age $=60$ years) undergoing reduced-intensity conditioning unrelated donor transplantation. Etanercept was administered twice weekly for 8 weeks after HCT, and ECP was given for 12 treatments, starting weekly on day 28 and tapering off by day 180 . GVHD occurred before the initiation of ECP in 10 patients. Cumulative incidence of grades II-IV aGVHD was similar to historical controls. Subjects developed predominantly moderate grade GVHD, with high rates of steroid responsiveness ( $84 \%$ day $56 \mathrm{CR} / \mathrm{PR}$ rate). However, this strategy was not effective at preventing a high incidence of cGVHD that resulted in late deaths. The 2-year OS for patients in this study was $56 \%$.

\section{Conclusion}

For patients with aGVHD who are SR or steroid dependent, there is no universally accepted therapy. ${ }^{11}$ Several agents with different mechanisms of action have been considered or continue to be evaluated as a second-line therapy (eg, anti-IL-2, anti-tumor necrosis factor [anti-TNF], anti-CD52, mycophenolate mofetil, tacrolimus, sirolimus, mesenchymal stromal cells and ECP). Several groups both in the US and in Europe are attempting to define the guidelines for use of ECP in aGVHD. Consensus statements are focused on patient selection for ECP treatment, protocol development for treatment schedules and durations, and response monitoring criteria. Das-Gupta et $\mathrm{al}^{43}$ published the UK consensus statement on the use of ECP in aGVHD. ECP is currently recommended as second-line therapy for patients with aGVHD, grades II-IV disease who are SR, steroid dependent or steroid intolerant. Two treatments/procedures of photopheresis on separate days should be initiated weekly for a minimum of eight cycles ( 8 weeks). Expected response rates vary by organ system involved, with skin GVHD having the highest overall response rate (ORR) of $60-80 \%$. In a systematic review by Abu-Dalle et al, ${ }^{44}$ ORR for aGVHD was 0.69 with organ-specific response being the highest in cutaneous aGVHD (0.84 ORR) followed by GI GVHD ( 0.65 ORR). Patients with higher grade aGVHD may benefit from aggressive, up-front ECP with three treatments per week for the first 4 weeks. Patients who have progressive aGVHD during this time may require additional therapy at the discretion of the treating physician. Emerging data on use of ECP as primary prophylaxis for aGVHD are somewhat encouraging and warrant further investigation using large controlled prospective studies.

\section{Clinical experience for cGVHD}

cGVHD has been characterized historically by autoimmune and alloimmune dysregulation occurring after the first 100 days of allo-HCT. ${ }^{45,46}$ A newer set of diagnostic criteria have been developed, and the definition of cGVHD has been refined to include the development of diagnostic features of immune dysfunction that may be present before day 100 and almost always occur within 3 years posttransplant. ${ }^{2}$

The clinical management of patients with extensive cGVHD is challenging due to the wide variability of disease manifestations, clinical severity, secondary infectious complications and treatment-related toxicity. ${ }^{47}$ Table 2 summarizes the outcome to ECP use as a second-line treatment for cGVHD.

In 2008, Flowers et $\mathrm{al}^{48}$ published the first prospective, multicenter randomized controlled Phase II clinical trial assessing utility of ECP in patients with cGVHD who were mostly steroid dependent. The study focused on skin involvement in cGVHD using total skin score (TSS) to track changes in skin in both treatment group and control group after 12 weeks of therapy. Patients were randomized to receive conventional therapy alone or ECP plus conventional therapy. ECP was delivered three times during week 1 then twice weekly from week 2 through 12 (ECP-responsive patients received two more ECP treatments every 4 weeks until week 24). The changes in TSS from baseline up to week 12 between both groups were not statistically significant $(-14.5 \%$ in ECP group and $-8.5 \%$ in control group, $p$ $=0.48$ ). At week 12, the proportion of patients who had at least a $25 \%$ decrease from baseline in TSS was $8.3 \%$ in the ECP group and $0 \%$ in the control group $(p=0.04)$. Clinical findings in this trial suggest that ECP may have a steroidsparing effect in cGVHD where, by week $12,25.0 \%(\mathrm{n}=12)$ of ECP-treated patients and $12.8 \%(n=6)$ of control-treated 
Table 2 Published response rates for ECP as a second-line treatment for CGVHD

\begin{tabular}{|c|c|c|c|c|c|c|c|c|}
\hline Author (year) & Study type & $\begin{array}{l}\text { Patients }(\mathrm{n}) / \\
\text { patient population }\end{array}$ & $\%$ ORR & $\begin{array}{l}\% \text { CR+PR } \\
\text { skin }\end{array}$ & $\begin{array}{l}\% \text { CR+PR } \\
\text { liver }\end{array}$ & $\begin{array}{l}\% \text { CR+PR } \\
\text { oral }\end{array}$ & $\%$ OS & Reference \\
\hline Greinix et al (1998) & Prospective & 15/adult & 93 & $100(15 / 15)$ & $90(9 / 10)$ & $100(11 / 11)$ & $93(14 / 15)$ & 74 \\
\hline Child et al (1999) & Prospective & I I/adult & NA & 100 & 17 & 75 & $82(9 / 11)$ & 75 \\
\hline Salvanzschi et al (200I) & Prospective & 14/pediatric & $64(9 / 14)$ & $83(10 / 12)$ & $67(6 / 9)$ & $67(8 / 12)$ & $79(11 / 14)$ & 13 \\
\hline Seaton et al (2003) & Prospective & 28/adult & 36 & $\begin{array}{l}48 \text { evaluable } \\
(10 / 21)\end{array}$ & $32(8 / 25)$ & $21(3 / 14)$ & $86(24 / 28)$ & 53 \\
\hline $\begin{array}{l}\text { Apisarnthanarax et al } \\
(2003)\end{array}$ & Retrospective & $32 /$ mixed & $56(18 / 32)$ & $59(19 / 32)$ & NA & NA & $59(19 / 32)$ & 65 \\
\hline Messina et al (2003) & Retrospective & 44/pediatric & 74 & 57 & 60 & NA & $77(34 / 44)$ & 37 \\
\hline Foss et al (2005) & Prospective & 25/adult (I pediatric) & $64(16 / 25)$ & $80(20 / 25)$ & NA & $46(6 / 13)$ & $60(15 / 25)$ & 52 \\
\hline Rubegni et al (2005) & Retrospective & 32/adult & $78(25 / 32)$ & $81(22 / 27)$ & $82(18 / 22)$ & 92 & NA & 64 \\
\hline Garban et al (2005) & Prospective & I5/mixed & $87(13 / 15)$ & $100(12 / 12)$ & $33(1 / 3)$ & NA & NA & 67 \\
\hline Bisaccia et al (2006) & Retrospective & |4/adult & NA & $50(7 / 14)$ & $60(3 / 5)$ & $43(3 / 7)$ & $71(10 / 14)$ & 76 \\
\hline Couriel et al (2006) & Retrospective & $71 /$ mixed & $6 I(43 / 7 I)$ & 57 & 71 & 78 & $18(|3 / 7|)$ & 50 \\
\hline Kanold et al (2007) & Retrospective & I5/pediatric & $73(11 / 15)$ & $75(9 / 12)$ & $82(9 / 11)$ & $86(6 / 7)$ & $67(10 / 15)$ & 57 \\
\hline Perseghin et al (2007) & Retrospective & $25 /$ mixed & $80(20 / 25)$ & $80(20 / 25)$ & $67(4 / 6)$ & $78(7 / 9)$ & $76(19 / 25)$ & 77 \\
\hline Flowers et al (2008) & $\mathrm{RCT}$ & $48 /$ mixed & & 40 & & 53 & $98(47 / 48)$ & 48 \\
\hline Jagasia et al (2009) & Retrospective & 43/adult & $74(32 / 43)$ & NA & NA & NA & 36 at 3 years & 78 \\
\hline Perotti et al $(2010)$ & Retrospective & 23/pediatric & $69.5(16 / 23)$ & 83 & $100(4 / 4)$ & $80(4 / 5)$ & 82.6 at 5 years & 58 \\
\hline Greinix et al (20II) & Prospective & 29/adult & & $31(9 / 29)$ & $50(3 / 6)$ & $70(14 / 20)$ & $100(29 / 29)$ & 49 \\
\hline Dignan et al (20I2) & Retrospective & 82 (69 evaluable)/adult & $79(65 / 82)$ & $92(57 / 62)$ & NA & $91(29 / 32)$ & $77(63 / 82)$ & 10 \\
\hline Tsirigotis et al (20I2) & Retrospective & $58 /$ mixed & $65.1(33 / 58)$ & $60(27 / 45)$ & $50(10 / 20)$ & $67(18 / 27)$ & $55(32 / 58)$ & 79 \\
\hline Hauntmann et al (2013) & Retrospective & 32/adult & $44(14 / 32)$ & $59(10 / 17)$ & $100(1 / 1)$ & $60(3 / 5)$ & $21 / 32$ & 80 \\
\hline Malagola et al (2016) & Retrospective & 49/adult & 80 & NA & NA & NA & $90(44 / 49)$ & 51 \\
\hline
\end{tabular}

Abbreviations: cGVHD, chronic graft-versus-host disease; $C R$, complete response; ECP, extracorporeal photopheresis; NA, not available; ORR, overall response rate; OS, overall survival; PR, partial response; RCT, randomized controlled trial.

patients had a $50 \%$ or greater reduction in the total daily dose of corticosteroids $(p=0.13)$. Findings also suggest that ECP resulted in a significant clinician-assessed disease response. In a follow-up study, Greinix et $\mathrm{a}^{49}$ further studied patients in the control group who were allowed to crossover to the ECP arm either before week 12 if they had progressive skin disease or after week 12 if inadequate skin response as defined by $<15 \%$ improvement in the TSS compared with baseline or a $\leq 25 \%$ reduction in corticosteroid dose. Similar but less robust trend in clinical benefit to the original study was observed where median percent decrease in TSS from baseline to week 24 was $-25.8 \%$. A $50 \%$ or more reduction in corticosteroid dose at week 24 was observed in $33 \%$ of patients. For extracutaneous GVHD, clinical benefit was most robust in oral mucosa ( $70 \%$ complete and partial resolution at week 24). These studies, however, are limited in their generalization due to their use of TSS as the primary end point, which has not been validated. As the steroid taper was left to the discretion of individual providers, it is challenging to compare the relative ability of ECP to spare steroids since there was no standard schedule. It is also unclear if additional benefit would have been seen in extracutaneous GVHD if a longer course of ECP therapy had been continued.
In a large uncontrolled case series, Couriel et a ${ }^{50}$ noted a $61 \%$ response rate in 71 patients with SR-cGVHD with the best responses observed in skin, liver, oral mucosa and eye. A CR was achieved in $20 \%$ of patients.

In 2016, Malagola et al ${ }^{51}$ published data of a multicenter retrospective analysis from The Italian Bone Marrow Transplant Group (Gruppo Italiano Trapianto di Midollo Osseo) supporting the use of ECP as a second-line treatment in patients with aGVHD and cGVHD. Forty-five patients had SR-aGVHD. Of those with aGVHD, $91 \%$ of patients achieved CR, but $33 \%$ went on to develop cGVHD. OS for aGVHD at 20 months was $65 \%$. Of the 49 patients with cGVHD, $45 \%$ and $35 \%$ of patients with SR-cGVHD achieved CR and PR, respectively. OS for cGVHD patients at 27 months was $90 \%$.

Foss et $\mathrm{a}^{52}$ reported an ORR of $64 \%$ in a prospective study on 25 patients with extensive SR cGVHD, and in $\sim 80 \%$ of patients, a reduction or discontinuation of IST was possible. These findings were similar to what was previously published by Seaton et al ${ }^{53}$ in 2003 where IST was stable or reduced in $86 \%$ of patients. The group prospectively studied 28 patients with advanced cGVHD treated with ECP and observed response to ECP even in those patients with extensive cutaneous cGVHD of 2 years duration. 
More recently, Dignan et a $1^{54}$ prospectively studied the impact of 6 months of treatment with ECP on skin scores and quality of life (QoL) in patients with SR-cGVHD. Seventy percent of patients had a CR or PR. Reduction in IST was achieved in $80 \%$ of patients. In a subset of patients who completed a QoL questionnaire using both the Lee chronic GVHD symptom scale and dermatology QoL index, both scores were significantly lower after 6 months of ECP (22 compared with $36, p=0.012$ and 3.4 compared with 6.9 , $p=0.009$ ).

Two recent systematic reviews concluded that use of ECP in cGVHD can be effective, and in certain cases allows for discontinuation of IST. ORRs and organ-specific efficacy were similar between both studies (with GI and lung cGVHD showing less response to ECP treatment). In the study by Abu-Dalle et al,${ }^{44}$ ORR for cGVHD was 0.64 . Response rates for cGVHD involving the skin and GI tract were 0.71 and 0.62 , respectively; in contrast, the ORR for cGVHD involving the lungs was only 0.15 . Additionally, ECP has been shown to be an extremely safe treatment modality. Concordant results were observed in the analysis by Malik et $\mathrm{a}^{55}$ where the pooled response rate for skin, oral, liver, musculoskeletal, ocular, GI and lung, and SR-cGVHD was 74\%, 72\%, 68\%, $64 \%, 60 \%, 53 \%$ and $48 \%$, respectively.

Many investigators administered ECP in patients with cGVHD according to the original publication by Edelson et $\mathrm{al}^{18}$ where they administered two ECP treatments on consecutive days every 2-4 weeks. Therefore, cGVHD has been treated with four to eight treatments per month, usually for 12-24 weeks. Subsequent tapering of ECP treatments, in most centers, is largely influenced by the ability to reduce or withdraw concomitant IST.

\section{Conclusion}

The majority of the clinical data on use of ECP for cGVHD are derived from retrospective studies with limited numbers of patients. Most promising results appear to be for use in cutaneous cGVHD with most reports quoting an ORR of $\sim 80 \%{ }^{44,55}$ The vast majority of published evidence on use of ECP for the treatment of cGVHD is focused on patients with SR or steroid-dependent cGVHD. There are very few studies currently available supporting the use of ECP as a first-line therapy of cGVHD. ${ }^{56} \mathrm{ECP}$ is a highly attractive therapeutic modality for cGVHD given its excellent safety and overall tolerance profile, both in children and in adults. In addition, patients benefit from the lack of global immunosuppression and the preservation of the graftversus-leukemia (GVL) effect. This favorable profile has encouraged leading experts in the field to suggest earlier use of ECP in the course of cGVHD, thus offering better control of GVHD and subsequently minimizing the risk of irreversible tissue damage and risk of death from systemic infections secondary to prolonged IST. Available data also suggested a survival advantage of ECP and improvement in the QoL. The issue remains that organ-specific response rates are variable with best responses observed in cutaneous, oral, ocular and possibly liver involvement. Responses for lung and GI involvement are less robust, and experience with ECP for cGVHD involving the lungs (bronchiolitis obliterans syndrome [BOS]) is limited. However, given the dismal prognosis of BOS, the efficacy of ECP for lung cGVHD still merits further investigation, and larger prospective studies are needed. To date, no specific treatment schedule has proven to be superior in terms of response rates making the collective interpretation of available literature difficult to assess. Thus, large, well-designed prospective studies are required to address these issues.

\section{Clinical experience in pediatrics}

Data on pediatric patients are limited to a few clinical reports using small numbers of patients. Performing ECP in pediatric patients is more complicated compared to adults due to challenges with vascular access, increased relative extracorporeal volumes, greater fluid shifts due to low body weight and psychological tolerance to procedure. However, ECP has been successfully utilized in children for both aGVHD and cGVHD.

In 2001, Salvaneschi et $\mathrm{al}^{13}$ treated 18 children with extensive cGVHD; they observed a $78 \%$ response rate and were able to wean steroids in $67 \%$ of patients. Messina et $\mathrm{al}^{37}$ treated 44 pediatric patients with cGVHD (considered extensive in $77 \%$ of patients). Significant improvement was observed in $59 \%$ of patients, and $44 \%$ of patients were able to discontinue all other IST. In 2007, Kanold et al ${ }^{57}$ published prospective data on the use of ECP for 27 pediatric patients with both aGVHD and CGVHD (12 and 15 patients, respectively), focusing on technical, biologic, immunologic, clinical and long-term follow-up issues. ORR was observed in 21 of 27 patients ( 11 with CR and 10 with PR) with few difficulties experienced by the investigators (with the main limiting factor being the vascular access). Authors concluded that ECP should be used as a first-line therapy in grade IV aGVHD, in addition to conventional pharmacological approaches, and in limited cGVHD. Furthermore, it should be considered as a second-line therapeutic modality in steroid-resistant grades II-III aGVHD and in extensive cGVHD. 
Perotti et a ${ }^{58}$ performed a retrospective review of 23 pediatric patients with extensive cGVHD and found an ORR of $69.5 \%$; organ-specific responses were $95 \%, 100 \%, 80 \%$ and $75 \%$ in cGVHD involving the skin, liver, oral mucosa and GI. Authors in this study suggest starting ECP at the onset of GVHD in addition to IST and continue ECP treatments until maximal response is achieved.

In an effort to counteract the challenge of treating pediatric patients with low bodyweight (as low as $15 \mathrm{~kg}$ ) for both aGVHD and cGVHD, Schneiderman et al ${ }^{59}$ reported the use of a sterile, closed-loop procedure, where patients received fluid boluses of normal saline or 5\% albumin to boost blood volume before and, if needed, during ECP procedures. The process was well tolerated by patients and therefore could extend the use of continuous-flow ECP to these patients with low body weight.

\section{Discussion}

Clinical use of ECP as a second-line therapeutic modality to treat GVHD has been extensively evaluated. However, most of these studies represent small case series or retrospective analyses that lack adequate control groups. Despite the abundance of clinical data spanning the last 3-4 decades, reaching a strong recommendation supported by high-quality evidence continues to be hampered by many confounding factors. Different studies have used a variety of ECP techniques on a variety of schedules for varying durations of time treating unknown quantities of PBMCs, all of which makes it challenging to assess the overall efficacy of this treatment modality. In addition, the lack of consensus on GVHD definitions, staging and response assessment make clinical outcomes difficult to interpret. Patient heterogeneity between studies further contributes to difficulty providing clear recommendations for when to optimally utilize this therapy.

Although different treatment options are available for second-line treatment of SR-GVHD, the choice of a particular therapeutic agent or treatment modality remains, to a large extent, a subject of treating physician's preference, a choice that is usually based on factors such as safety profile, physician's experience with the particular treatment and the presence of encouraging clinical data supporting its use. The safety profile of ECP is excellent. It is very well tolerated even in children with body weight as low as $10 \mathrm{~kg} \cdot{ }^{13,37,60}$ Several second-line therapies commonly used for SR-GVHD cause profound suppression of T-cell function (eg, ATG, alemtuzumab, daclizumab and pentostatin), thus significantly increasing the risk of viral reactivation in exposed patients. In contrast, ECP was found to have a favorable profile with limited toxicity, no increased risk for infections and no concerns for increased viral reactivations during ECP treatment. ${ }^{11,48,50}$

This lack of global immunosuppression is particularly beneficial in patients who have undergone HCT for malignant diseases where preserving the GVL effect of donor T-lymphocytes is essential in eradicating the hematological malignancy. In fact, patients receiving ECP respond normally to new immune challenges such as exposure to pathogens or vaccines. ${ }^{61} \mathrm{ECP}$ in patients with GVHD does not result in an increased incidence of malignant relapse, and patients undergoing long-term ECP therapy for CTCL and scleroderma do not develop the infections or secondary malignancies that are associated with conventional immunosuppressants. ${ }^{62,63}$

Because intravenous access is required to perform ECP, patients are at risk for catheter-related complications including infection and thrombosis. Kanold et al ${ }^{57}$ reported that $2.5 \%$ (19 of 750) ECP procedures in 27 children were prematurely suspended due to CVL-related issues. Schneiderman et al observed 44 episodes (13\%) of CVL occlusions that caused machine alarms. These were treated with normal saline flushes or TPA and required CVL change on two occasions. ${ }^{59}$

Steroid sparing should be an important goal of secondline therapy, a feature that has not been consistently examined across ECP studies. One important consideration when using ECP especially for SR-cGVHD is the time needed to achieve an objective response. Data from large controlled studies support the notion that extended courses of ECP (beyond 12 weeks) may be necessary to achieve the desired response especially in patients with advanced cutaneous involvement (as in lichenoid and sclerodermoid cGVHD). ${ }^{48,49}$

Some authors have suggested that earlier use of ECP improves response rates and increases the likelihood of being able to discontinue the use of steroids and other IST; however, this finding is inconsistent and needs further evaluation. Studies are ongoing to determine if early initiation of an aggressive ECP regimen provides additional disease control while limiting the need for additional IST. A randomized Phase II study for the evaluation of extracorporeal photopheresis (ECP) in combination with corticosteroids for the initial treatment of aGVHD was recently completed (NCT00609609). Another ongoing study is the Therakos trial (NCT02524847), which is a single-arm study aiming to assess the efficacy of Uvadex (Methoxsalen) in conjunction with the Therakos Cellex photopheresis system in pediatric patients with SR-aGVHD utilizing a novel, up-front aggressive ECP treatment regimen. 


\section{Summary}

- Phases I and II data suggest that ECP is an effective treatment for aGVHD and cGVHD with response rates ranging from $40 \%$ to $81 \%$. ECP is safe and well tolerated. ${ }^{12,13,50,52,64}$

- Response rates for cutaneous cGVHD are encouraging $(\sim 80 \%)$. Visceral and lung cGVHD responses have been less consistent across studies. ${ }^{44,55}$

- ECP has steroid-sparing properties; does not result in systemic immunosuppression; no reported increase in infectious complications in patients receiving ECP treatment; and no negative effect on GVL observed.

- No treatment frequency or duration of therapy has been proven to be ideal in improving response rates.

- The use of ECP as a second-line therapy is regarded as level C-1 strength of recommendation based on level II quality of evidence. Some evidence suggests that the earlier the ECP is administered, the greater the likelihood of achieving a CR/PR. ${ }^{50,56,65}$

- ECP may offer a survival benefit and improvement in QoL as well. ${ }^{66}$

- Large randomized trials are needed to better assess its efficacy and to answer questions such as when and for which patients should this therapy be offered.

\section{Disclosure}

Dr Jacobsohn has received a consulting fee from Mallinckrodt (Cellex ${ }^{\circledR}$ ECP system) for the pediatric clinical trial development. The authors report no other conflicts of interest in this work.

\section{References}

1. Przepiorka D, Weisdorf D, Martin P, et al. 1994 consensus conference on acute GVHD grading. Bone Marrow Transplant. 1995;15:825-828.

2. Filipovich AH, Weisdorf D, Pavletic S, et al. National Institutes of Health consensus development project on criteria for clinical trials in chronic graft-versus-host disease: I. Diagnosis and staging working group report. Biol Blood Marrow Transplant. 2005;11(12): 945-956.

3. Wingard JR, Majhail NS, Brazauskas R, et al. Long-term survival and late deaths after allogeneic hematopoietic stem cell transplantation. J Clin Oncol. 2011;29(16):2230-2239.

4. Pasquini MC, Wang Z, Horowitz MM, Gale RP. 2010 report from the Center for International Blood and Marrow Transplant Research (CIBMTR): current uses and outcomes of hematopoietic cell transplants for blood and bone marrow disorders. Clin Transpl. 2010:87-105.

5. Salmasian H, Rohanizadegan M, Banihosseini S, et al. Corticosteroid regimens for treatment of acute and chronic graft versus host disease (GvHD) after allogenic stem cell transplantation. Cochrane Database Syst Rev. 2010;1:CD005565. doi: 10.1002/14651858.CD005565.pub2.

6. Stewart BL, Storer B, Storek J, et al. Duration of immunosuppressive treatment for chronic graft versus-host disease. Blood. 2004;104(12): 3501-3506.

7. Horwitz ME, Sullivan KM. Chronic graft-versus host disease. Blood Rev. 2003;20(1):15-27.
8. Lee SJ. New approaches for preventing and treating chronic graftversus-host disease. Blood. 2006;105(11):4200-4206.

9. Lee SJ, Vogelsang G, Flowers MED. Chronic graft-versus-host disease. Biol Blood Marrow Transplant. 2003;9(4):215-233. Review.

10. Dignan FL, Clark A, Amrolia P, et al. Diagnosis and management of acute graft-versus-host disease. Br J Haematol. 2012;158(1):30-45.

11. Martin PJ, Rizzo JD, Wingard JR, et al. First- and second-line systemic treatment of acute graft-versus-host disease: recommendations of the American Society of Blood and Marrow Transplantation. Biol Blood Marrow Transplant. 2012;18(8):1150-1163.

12. Greinix HT, Volc-Platzer B, Knobler RM. Extracorporeal photochemotherapy in the treatment of severe graft-versus-host disease. Leuk Lymphoma. 2000;36(5-6):425-434.

13. Salvaneschi L, Perotti C, Zecca M, et al. Extracorporeal photochemotherapy for treatment of acute and chronic GVHD in childhood. Transfusion. 2001;41:1299-1305.

14. Owsianowski M, Golollnick H, Siegert W, Schwerdtfeger R, Orfanos CE. Successful treatment of chronic graft-versus-host disease with extracorporeal photopheresis. Bone Marrow Transplant. 1994;14(5):845-848.

15. Del Fante C, Scudeller L, Martinasso A, Viarengo G, Perotti C. Comparison of two automated mononuclear cell collection systems in patients undergoing extracorporeal photopheresis: a prospective crossover equivalence study. Transfusion. 2016;56(8):2078-2084.

16. Brosig A, Hähnel V, Orsó E, Wolff D, Holler E, Ahrens N. Technical comparison of four different extracorporeal photopheresis systems. Transfusion. 2016;56(10):2510-2519.

17. Kapadia E, Wong E, Perez-Albuerne E, Jacobsohn D. Extracorporeal photopheresis performed on the CELLEX ${ }^{\circledR}$ compared with the UVARXTS $₫$ instrument is more efficient and better tolerated in children with steroid-refractory graft-versus-host disease. Pediatr Blood Cancer. 2015;62(8):1485-1488.

18. Edelson R, Berger C, Gasparro F, et al. Treatment of cutaneous T-cell lymphoma by extracorporeal photochemotherapy. Preliminary results. N Engl J Med. 1987;316(6):297-303.

19. Berger C, Hanlon D, Kanada D, Girardi M, Edelson R. Transimmunization, a novel approach for tumor immunotherapy. Transfus Apher Sci. 2002;26(3):205-216.

20. Bladon J, Taylor P. Extracorporeal photopheresis: a focus on apoptosis and cytokines. J Dermatol Sci. 2006;43(2):85-94.

21. Cimino G, Gamper H, Isaacs S, Hearst J. Psoralens as photoactive probes of nucleic acid structure and function: organic chemistry, photochemistry, and biochemistry. Annu Rev Biochem. 1985;54:1151-1193.

22. Gasparro F, Dall'Amico R, Goldminz D, Simmons E, Weingold D. Molecular aspects of extracorporeal photochemotherapy. Yale J Biol Med. 1989;62(6):579-593.

23. Marks D, Rockman S, Oziemski M, Fox R. Mechanisms of lymphocytotoxicity induced by extracorporeal photochemotherapy for cutaneous T cell lymphoma. J Clin Invest. 1990;86(6):2080-2085.

24. Lorenz K, Rommel K, Mani J, et al. Modulation of lymphocyte subpopulations by extracorporeal photopheresis in patients with acute graft-versus-host disease or graft rejection. Leuk Lymphoma. 2015;56(3):671-675.

25. Heshmati F. Updating ECP action mechanisms. Transfus Apher Sci. 2014;50(3):330-339.

26. Foss F, Gorgun G, Miller K. Extracorporeal photopheresis in chronic graft-versus host disease. Bone Marrow Transplant. 2002;29(9):719-725.

27. Fimiani M, Di Renzo M, Rubegni P. Mechanism of action of extracorporeal photochemotherapy in chronic graft-versus-host disease. $\mathrm{Br} J$ Dermatol. 2004;150(6):1055-1060.

28. Bredberg A, Forsgren A. Effects of vitro PUVA on human leukocyte function. Br J Dermatol. 1984;111(2):159-168.

29. Deeg HJ, Erickson K, Storb R, Sullivan KM. Photoinactivation of lympho-hemopoietic cells: studies in transfusion medicine and bone marrow transplantation. Blood Cells. 1992;18(1):151-162.

30. Kapoor N, Pelligrini AE, Copelan EA, et al. Psoralen plus Ultraviolet A (PUVA) in the treatment of chronic graft versus host disease: preliminary experience in standard treatment resistant patients. Semin Hematol. 1992;29(2):108-112. 
31. Barr ML. Immunomodulation in transplantation with photopheresis. Artif Organs. 1996;20(8):971-973.

32. Yoo EK, Rook AH, Elenitsas R, Gasparro FP, Vowels BR. Apoptosis induction by ultraviolet light $\mathrm{A}$ and photochemotherapy in cutaneous T-cell lymphoma: relevance to mechanism of therapeutic action. J Invest Dermatol. 1996;107(2):235-242.

33. Aringer M, Graninger WB, Smolen JS, et al. Photopheresis treatment enhances CD95 (FAS) expression in circulating lymphocytes of patients with systemic sclerosis and induces apoptosis. Br J Rheumatol. 1997;36(12):1276-1282.

34. Bladon J, Taylor PC. Extracorporeal photopheresis induces apoptosis in the lymphocytes of cutaneous T-cell lymphoma and graft-versus-host disease patients. Br J Haematol. 1999;107(4):707-711.

35. Berger CL, Xu AL, Hanlon D, et al. Induction of tumor-loaded dendritic cells. Int J Cancer. 2001;91(4):438-447.

36. Ullrich SE. Photoinactivation of T-cell function with psoralen and UVA radiation suppresses the induction of experimental murine graft-versushost disease across major histocompatibility barriers. J Invest Dermatol. 1991;96(3):303-308.

37. Messina C, Locatelli F, Lanino E, et al. Extracorporeal photochemotherapy for paediatric patients with graft-versus-host disease after haematopoietic stem cell transplantation. Br J Haematol. 2003;122:118-127.

38. Greinix HT, Knobler RM, Worel N, et al. The effect of intensified extracorporeal photochemotherapy on long-term survival in patients with severe acute graft-versus-host disease. Haematologica. 2006;91(3):405-408.

39. Jagasia M, Greinix H, Robin M, et al. Extracorporeal photopheresis versus anticytokine therapy as a second-line treatment for steroidrefractory acute GVHD: a multicenter comparative analysis. Biol Blood Marrow Transplant. 2013;19(7):1129-1133.

40. Shaughnessy PJ, Bolwell BJ, van Besien K, et al. Extracorporeal photopheresis for the prevention of acute GVHD in patients undergoing standard myeloablative conditioning and allogeneic hematopoietic stem cell transplantation. Bone Marrow Transplant. 2010;45(6):1068-1076.

41. Miller KB, Roberts TF, Chan G, et al. A novel reduced intensity regimen for allogeneic hematopoietic stem cell transplantation associated with a reduced incidence of graft-versus-host disease. Bone Marrow Transplant. 2004;33(9):881-889.

42. Kitko CL, Braun T, Couriel DR, et al. Combination therapy for graftversus-host disease prophylaxis with etanercept and extracorporeal photopheresis: results of a phase II clinical trial. Biol Blood Marrow Transplant. 2016;22(5):862-868.

43. Das-Gupta E, Dignan F, Shaw B, et al. Extracorporeal photopheresis for treatment of adults and children with acute GVHD: UK consensus statement and review of published literature. Bone Marrow Transplant. 2014;49(10):1251-1258.

44. Abu-Dalle I, Reljic T, Nishihori T, et al. Extracorporeal photopheresis in steroid-refractory acute or chronic graft-versus-host disease: results of a systematic review of prospective studies. Biol Blood Marrow Transplant. 2014;20(11):1677-1686.

45. Sullivan KM, Shulman HM, Storb R, et al. Chronic graft-versus-host disease in 52 patients: adverse natural course and successful treatment with combination immunosuppression. Blood. 1981;57(2):267-276.

46. Shulman HM, Sullivan KM, Weiden PL, et al. Chronic graft-versus-host syndrome in man. A long-term clinicopathologic study of 20 Seattle patients. Am J Med. 1980;69(2):204-217.

47. Flowers ME, Parker PM, Johnston LJ, et al. Comparison of chronic graft-versus-host disease after transplantation of peripheral blood stem cells versus bone marrow in allogeneic recipients: longterm follow-up of a randomized trial. Blood. 2002;100:415-419.

48. Flowers ME, Apperley JF, van Besien K, et al. A multicenter prospective phase 2 randomized study of extracorporeal photopheresis for treatment of chronic graft-versus host disease. Blood. 2008;112(7):2667-2674.

49. Greinix HT, van Besien K, Elmaagacli AH, et al. Progressive improvement in cutaneous and extracutaneous chronic graft-versus-host disease after a 24-week course of extracorporeal photopheresis - results of a crossover randomized study. Biol Blood Marrow Transplant. 2011;17(12):1775-1782.
50. Couriel DR, Hosing C, Saliba R, et al. Extracorporeal photochemotherapy for the treatment of steroid-resistant chronic GVHD. Blood. 2006;107(8):3074-3080.

51. Malagola M, Cancelli V, Skert C, et al. Extracorporeal photopheresis for treatment of acute and chronic graft versus host disease: an Italian Multicentric Retrospective Analysis on 94 patients on behalf of the Gruppo Italiano Trapianto di Midollo Osseo. Transplantation. 2016;100(12):e147-e155.

52. Foss FM, DiVenuti GM, Chin K, et al. Prospective study of extracorporeal photopheresis in steroid refractory or steroid-resistant extensive chronic graft-versus-host disease: analysis of response and survival incorporating prognostic factors. Bone Marrow Transplant. 2005; 35(12):1187-1193.

53. Seaton ED, Szydlo RM, Kanfer E, Apperley JF, Russell-Jones R. Influence of extracorporeal photopheresis on clinical and laboratory parameters in chronic graft-versus-host disease and analysis of predictors of response. Blood. 2003;102(4):1217-1223.

54. Dignan FL, Aguilar S, Scarisbrick JJ, et al. Impact of extracorporeal photopheresis on skin scores and quality of life in patients with steroid-refractory chronic GVHD. Bone Marrow Transplant. 2014;49(5):704-708.

55. Malik MI, Litzow M, Hogan W, et al. Extracorporeal photopheresis for chronic graft-versus-host disease: a systematic review and metaanalysis. Blood Res. 2014;49(2):100-106

56. Wolff D, Gerbitz A, Ayuk F, et al. Consensus conference on clinical practice in chronic graft-versus-host disease (GVHD): first-line and topical treatment of chronic GVHD. Biol Blood Marrow Transplant. 2010;16(12):1611-1628.

57. Kanold J, Merlin E, Halle P, et al. Photopheresis in pediatric graftversus-host disease after allogeneic marrow transplantation: clinical practice guidelines based on field experience and review of the literature. Transfusion. 2007;47(12):2276-2289.

58. Perotti C, Del Fante C, Tinelli C, et al. Extracorporeal photochemotherapy in graft-versus-host disease: a longitudinal study on factors influencing the response and survival in pediatric patients. Transfusion. 2010;50(6):1359-1369.

59. Schneiderman J, Jacobsohn DA, Collins J, Thormann K, Kletzel M. The use of fluid boluses to safely perform extracorporeal photopheresis (ECP) in low-weight children: a novel procedure. J Clin Apher. 2010;25(2):63-69.

60. Halle P, Paillard C, D'Incan M, et al. Successful extracorporeal photochemotherapy for chronic graft-versus-host disease in pediatric patients. $J$ Hematother Stem Cell Res. 2002;11(3):501-512.

61. Suchin KR, Cassin M, Washko R, et al. Extracorporeal photochemotherapy does not suppress T- or B-cell responses to novel or recall antigens. J Am Acad Dermatol. 1999;41(6):980-986.

62. McKenna KE, Whittaker S, Rhodes LE, et al; British Photodermatology Group; UK Skin Lymphoma Group. Evidence-based practice of photopheresis 1987-2001: a report of a workshop of the British Photodermatology Group and the U.K. Skin Lymphoma Group. Br J Dermatol. 2006;154(1):7-20.

63. Lim HW, Edelson RL. Photopheresis for the treatment of cutaneous T-cell lymphoma. Hematol Oncol Clin North Am. 1995;9:1117-1126.

64. Rubegni P, Cuccia A, Sbano P, et al. Role of extracorporeal photochemotherapy in patients with refractory chronic graft-versus-host disease. Br J Haematol. 2005;130(2):271-275.

65. Apisarnthanarax N, Donato M, Korbling M, et al. Extracorporeal photopheresis therapy in the management of steroid-refractory or steroid-dependent cutaneous chronic graft-versus-host disease after allogeneic stem cell transplantation: feasibility and results. Bone Marrow Transplant. 2003;31(6):459-465.

66. Couriel DR. Ancillary and supportive care in chronic graft-versushost disease. Best Pract Res Clin Haematol. 2008;21(2):291-307. doi: 10.1016/j.beha.2008.02.014.

67. Garban F, Drillat P, Makowski C, et al. Extracorporeal chemophototherapy for the treatment of graft-versus-host disease: hematologic consequences of short-term, intensive courses. Haematologica. 2005;90(8):1096-1101. 
68. Berger M, Pessolano R, Albiani R, et al. Extracorporeal photopheresis for steroid resistant graft versus host disease in pediatric patients: a pilot single institution report. $J$ Pediatr Hematol Oncol. 2007;29(10):678-687.

69. Calore E, Calo A, Tridello G, et al. Extracorporeal photochemotherapy may improve outcome in children with acute GVHD. Bone Marrow Transplant. 2008;42(6):421-425.

70. Perfetti P, Carlier P, Strada P, et al. Extracorporeal photopheresis for the treatment of steroid refractory acute GVHD. Bone Marrow Transplant. 2008;42(9):609-617.

71. Gonzalez-Vicent M, Ramirez M, Perez A, Lassaletta A, Sevilla J, Diaz MA. Extracorporeal photochemotherapy for steroid-refractory graft versus- host disease in low-weight pediatric patients. Immunomodulatory effects and clinical outcome. Haematologica. 2008;93(8): $1278-1280$

72. Gonzalez Vicent M, Ramirez M, Sevilla J, Abad L, Diaz MA. Analysis of clinical outcome and survival in pediatric patients undergoing extracorporeal photopheresis for the treatment of steroid-refractory GVHD. J Pediatr Hematol Oncol. 2010;32(8):589-593.

73. Berger M, Albiani R, Sini B, Fagioli F. Extracorporeal photopheresis for graft-versus-host disease: the role of patient, transplant, and classification criteria and hematologic values on outcome-results from a large single-center study. Transfusion. 2015;55(4):736-747.
74. Greinix HT, Volc-Platzer B, Rabitsch W, et al. Successful use of extracorporeal photochemotherapy in the treatment of severe acute and chronic graft-versus-host disease. Blood. 1998;92(9):3098-3104.

75. Child FJ, Ratnavel R, Watkins P, et al. Extracorporeal photopheresis (ECP) in the treatment of chronic graft-versus-host disease (GVHD). Bone Marrow Transplant. 1999;23(9):881-887.

76. Bisaccia E, Palangio M, Gonzalez J, et al. Treatment of extensive chronic graft-versus-host disease with extracorporeal photochemotherapy. J Clin Apher. 2006;21(3):181-187.

77. Perseghin P, Galimberti S, Balduzzi A, et al. Extracorporeal photochemotherapy for the treatment of chronic graft-versus-host disease: trend for a possible cell dose-related effect? Ther Apher Dial. 2007;11(2):85-93.

78. Jagasia MH, Savani BN, Stricklin G, et al. Classic and overlap chronic graft-versus-host disease (cGVHD) is associated with superior outcome after extracorporeal photopheresis (ECP). Biol Blood Marrow Transplant. 2009;15(10):1288-1295.

79. Tsirigotis P, Kaloyannidis P, Papalexandri A, et al. Extracorporeal photopheresis in the treatment of chronic graft-versus-host disease. The Hellenic experience: a study by the Hellenic association of hematology. Transfus Apher Sci. 2012;46(2):173-180.

80. Hautmann AH, Wolff D, Hahn J, et al. Extracorporeal photopheresis in 62 patients with acute and chronic GVHD: results of treatment with the COBE Spectra system. Bone Marrow Transplant. 2013;48(3):439-445.
International Journal of Clinical Transfusion Medicine

\section{Publish your work in this journal}

International Journal of Clinical Transfusion Medicine is an international, peer-reviewed, open access, online journal publishing clinicalexperimental, policy-making and evidence-based practices of all topics pertaining to clinical transfusion medicine. Original research, short reports, reviews, case reports and commentaries are invited.
Dovepress

The manuscript management system is completely online and includes a very quick and fair peer-review system, which is all easy to use. Visit http://www.dovepress.com/testimonials.php to read real quotes from published authors.

Submit your manuscript here: https://www.dovepress.com/international-journal-of-clinical-transfusion-medicine-journal 